Frank Lindblad Monica Dalen

Finn Rasmussen

Bo Vinnerljung

Anders Hjern

\section{School performance of international adoptees better than expected from cognitive test results}

Received 9 June 2008

Accepted: 29 September 2008

Published online: 20 January 2009

F. Lindblad, MD, PhD ( $\square)$

Department of Neuroscience, Child

and Adolescent Psychiatry

University Hospital of Uppsala

75185 Uppsala, Sweden

Tel.: +46-18/611-8887

Fax: +46-18/611-2565

E-Mail: frank.lindblad@neuro.uu.se

F. Lindblad, MD, PhD

Stress Research Institute

Stockholm University

10691 Stockholm, Sweden

M. Dalen, $\mathrm{PhD}$

Department of Special Needs Education

University of Oslo

PB 1140, Blindern

0317 Oslo, Norway

F. Rasmussen, $\mathrm{MD}, \mathrm{PhD}$

Child and Adolescent Public Health

Epidemiology Group

Department of Public Health Sciences

Karolinska Institutet

17176 Stockholm, Sweden

B. Vinnerljung, $\mathrm{PhD} \cdot \mathrm{A}$. Hjern, $\mathrm{MD}, \mathrm{PhD}$ Centre for Epidemiology

National Board of Health and Welfare

10630 Stockholm, Sweden

B. Vinnerljung, $\mathrm{PhD}$

Institute for Evidence-based Social Work

Practice

National Board of Health and Welfare

10630 Stockholm, Sweden

\author{
A. Hjern, MD, PhD \\ Department of Women's and \\ Children's Health \\ Uppsala University \\ 75185 Uppsala, Sweden
}

Abstract Objective To investigate school performance of international adoptees in relation to their cognitive competence. Method From the population of all male Swedish residents born 1973-1976, registered in the census 1985 and with complete test scores from military conscription, the following study groups were identified: Korean adoptees $(n=320)$, non-Korean adoptees $(n=1,125)$, siblings (children born by adoptive parents, $n=190)$ and Swedish majority comparisons $(n=142,024)$. Global scores from intelligence tests at conscription were compared with grade points from the last compulsory school year (year 9). Linear and logistic regression was applied in statistical analyses. Results The mean grade points in theoretical subjects were lower in non-Korean adoptees than in the majority population, but when global test scores from military conscription were adjusted for, outcomes were significantly better, equal for physics, than in the majority population. The grade points of Korean adoptees were higher than in the majority population and the same held true after adjusting for global test scores. When SES was taken into account, the risk of poor school perfor- mance (only completed lower subject levels) increased in nonKorean adoptees compared to models only adjusted for age and sex. Conclusion Male international adoptees generally perform better in school than expected by their cognitive competence. A cognitive evaluation is important in the assessment of adoptees with learning difficulties.

Key words adoption cognition - intelligence school 


\section{Introduction}

The psychiatric development of international adoptees has been the focus of many scientific reports. In the largest ( $n=2.148)$ study on international adoptees (10-15 years of age) from the last century, Verhulst, Althaus and Versluis-den Bieman reported a higher frequency of adopted children with psychiatric problem behaviour [measured through the parental version of Child Behavior Check List (CBCL)] compared with Dutch non-adopted children of the same age [1]. A follow-up study $(n=1.484)$, using a standardized psychiatric interview procedure-found that international adoptees had higher risks of severe mental health problems than non-adopted peers [2]. A Swedish register study from 2002 (11.320 international adoptees and several comparison groups including majority population peers) reported higher risks for suicide (OR 3.6), suicide attempt (OR 3.6) and psychiatric hospital care (OR 3.2) after adjustment for major socio-demographic confounders [3]. A recent meta-analysis concludes that international adoptees are referred more often to mental health services than comparisons [4]. Thus, there seems to be consensus in adoption research about increased risks of severe psychiatric problems in international adoptees, even though there is uncertainty about the magnitude of these over-risks. These results raise important questions for professionals and researchers in the child psychiatric field concerning which are the most important background factors for this negative development and what preventive measures could be taken.

School adaptation and performance may be examples of such risk factors, which are possible to influence through interventions. Jablonska et al. found that the risk for hospital admission due to self-harm increased steeply in a stepwise manner with decreasing grade point averages from the last compulsory school year, Hazard Ratio 6.7 in those with the lowest level of grade point averages compared to those with the highest [5]. Along the same line, an educational (and family service) program from preschool to third grade was associated with a number of positive psychosocial outcomes, including a trend for lower rate of depressive symptoms, at 24 years of age [6].

A recent meta-analysis has reported that national and international adoptees do not perform as well as non-adopted children of the same age at school while there are only "negligible" differences in IQ [7]. The authors introduced the term "adoption decalage" to describe the discrepancy between cognitive prerequisites (IQ) and school performance and related this to "socio-emotional problems related to their adoption status". However, even though the hypothesis is based on a meta-analysis, there is still some uncer- tainty concerning its validity. Firstly, IQ was actually lower in adoptees in studies concerning comparisons with environmental siblings or peers as well as with general population peers. Secondly, only eight reviewed studies involved both cognitive and school related outcomes. Of these, only two explicitly concerned international adoptees and only one supported the adoption decalage hypothesis $[8,9]$. The latter concerned early infant adoption with, for instance, a mean age of 7 weeks, $S D=3$, at adoption for the largest (108/159) study group (from Sri Lanka) [9]. This selection makes it difficult to draw valid conclusions about international adoptees in general.

Contrasting results on intellectual performance have recently been reported by Odenstad et al. [10] With the exception of Korean adoptees (results were on par with non-adoptees), Swedish international adoptees had lower test scores, 3.67 on a 9 graded scale compared to 5.11 in the majority population. Interestingly, Swedish international adoptees seem to reach similar educational levels as non-adoptees [11] and (male) non-Korean adoptees reach higher educational levels than expected from their cognitive test results [12]. Even though these findings thus seem to contradict the "decalage hypothesis", one may still claim that educational level may be highly sensitive to familial expectations about academic career. Since we know from previous studies that Swedish adoptive families are socially advantaged-probably implying high educational expectations - this may constitute a bias when using education level as a measure of school success. In order to further elucidate these issues, this study was designed to study the interplay between cognitive performance in male adoptees-as expressed in tests at conscription and school performance, measured by grade points from the 9th year at school, which is the final compulsory school year in Sweden. The following research questions were approached:

- Do international adoptees perform better/worse at school-compared to siblings and non-adopted peers-than expected from intelligence test scores?

- Is the relation between intelligence test scores and school performance similar in groups with high (Korean adoptees) and low (non-Korean adoptees) mean intelligence scores?

- Does the SES of the adoptive family influence the relation between intelligence and school performance?

\section{Method}

The study was based on record-linkages between national registers held by Statistics Sweden and the 
National Archives. These registers were linked to each other and to population censuses by use of the unique ten digits ID numbers given to all Swedish residents at birth or immigration, making it possible to study patterns of outcome factors, also adjusting for socioeconomic and other relevant factors. National population registers minimize attrition problems and cover whole national cohorts [13]. Informed consent is not possible to obtain in this kind of studies since all individuals are anonymous to the researchers and thus not possible to reach. Moreover, research on international adoption in Sweden can take advantage of the high number of adoptees in the country, 47.000 adoptions between 1968 and 2006 [14] —which also means representation of a large variety of donor countries. The study was approved by the regional ethics committee at Karolinska Institutet.

\section{Study population}

The study population comprised all Swedish residents who were born 1973-1976 according to the MultiGeneration Register and who were also present in the Population and Housing Census (PHCs) of 1985. Only men with complete test scores from military conscription during the time period when "enlistment battery 80" was in use (until September 1994) were included in the study. About $94.8 \%$ of the Korean adoptees, $89.9 \%$ of the non-Korean adoptees, $97.2 \%$ of the siblings and $94.3 \%$ of the Swedish majority population born 1973-1976 were included of those eligible according to their date of conscription. Four study groups were created based on information about adoption from the multi-generation register. Information about country and year of birth and immigration of the study subjects and their parents were retrieved from the register of the total population. The international adoptee groups consisted of individuals born outside the Western countries (Europe, North America and Australia) who immigrated to Sweden before 11 years of age and had two Swedish-born adoptive parents. The international adoptees were divided into two groups, Korean adoptees $(N=320)$ and non-Korean adoptees $(N=1,125)$. The major ( $>50$ individuals during the period) countries of origin for the non-Koran adoptees were, in order of size: India (231), Thailand (213), Chile (151), Sri Lanka (99), Colombia (95), Ethiopia (86) and Ecuador (74). Siblings of international adoptees were defined as biological offspring of mothers that were recorded in the Multi-Generation Register as an adoptive mother of a foreign-born child $(N=190)$. The Swedish majority population consisted of Swedish-born offspring of two Swedish-born parents who were not recorded as adoptive parents $(N=142,024)$.

\section{The National School Register}

The National School Register is administered jointly by the Swedish School Authority (Skolverket) and Statistics Sweden. The database encompasses information on individual educational performance (grade points by subject as well as summary grade points) for all students graduating from class nine in public schools since 1988. Non-public schools, which comprise fewer than $5 \%$ of all Swedish schools, have been included since 1993. The grading system during 19881996 consisted of a five point scale. The grading level in each school was under national supervision by the Swedish School Authority through national tests in key subjects. In 1997 the grading and the national supervision system were changed radically. For this study, grades from five subjects were analysed: Physics, Swedish, History, Sports education and Music. The first three were also analysed together as "theoretical subjects" and the two latter as "practical subjects".

During this period the Swedish national school system also practiced "ability grouping" in Mathematics and English for the last three school years [15]. Pupils were at age 13 sorted into low or high level classes in Mathematics and English. Henceforth, completed levels of either type are used as outcome variables for mathematics and English, since grade points from these different levels cannot be compared. The quality of the data in the National School Register is high and summary statistics are published regularly [16].

\section{Test scores at military conscription}

The Military Service Conscription Register comprises information about male residents in Sweden who have been conscripted for military service. During the years covered by this study all male Swedish citizens, with the exception of individuals with an obvious and severe disability, were obliged by law to attend conscription for military service.

At conscription, the young men undergo a standardized physical health examination and-since 1944-an intelligence test. The original test battery has been revised several times. The "enlistment battery 80 " was used between 1980 and 1994, measuring intellectual performance by four subtests representing logical (understanding and applying written instructions), spatial (mental "folding" of objects), verbal (knowledge of synonyms), and technical capabilities (knowledge of chemistry and physics) [17]. All test scores, and a global score derived as a summary score from the four subtests, are standardized to give a Gaussian distribution of scores between 1 and 9 . Higher values indicate enhanced intellectual compe- 
tence. Due to military secrecy, the tests are not available for persons outside the Swedish conscription authority. However, a construct validity analysis of the global scale has been published [18]. In a confirmatory factor analysis using the LISREL program, it was demonstrated that the global score could be "seen as a good estimate of general intellectual competence defined as an ability to solve complex problems" [18].

\section{Independent variables/potential confounding factors}

Data on maternal education was obtained from the Swedish Educational Register (if available from the register of 2001 and otherwise from the registers of 1995 or 1990) categorised as Short ( $<12$ years), Medium (12-13 years), Long (14-15 years) and Very Long (16+). The socio-economic (SES) and single parent status of the household was identified in the Swedish Population and Housing Census of 1985. Socio-economic groups were defined according to a classification created by Statistics Sweden, which is based on occupation but also takes the level of education, type of production and position at work of the head of the household into account [19]. Geographical location of the home (residency) was categorised as city, town and rural, based on a ninecategory-scale (h-region) provided by Statistics Sweden.

\section{Data analysis}

Linear regression was used to analyse grade points from the final ninth grade in the Swedish compulsory school system. Individuals with an incomplete course were excluded from the analysis of that particular course. Some schools did not assign specific grades in history and physics and individuals from these schools were also excluded from these specific analyses.

Logistic regression was used to analyse having completed the lower level of a. English and b. Mathematics in the conscripts with complete test scores as defined above. In this analysis a first model was adjusted for year of birth only, while test scores were added in the second and socio-economic confounders in the third and final model. Year of birth was entered as a continuous variable in all analyses because of the slight but systematic increase of grade point averages over the years. All analyses were made with the aid of the SPSS 13.0 software.

\section{Results}

SES was higher in the adoptive families (highest in families with non-Korean adoptees) than in the majority population and maternal education followed the same pattern (Table 1).

Grade points from the ninth and final year of the Swedish compulsory school system and mean global

Table 1 Socio-demographic variables in the study groups

\begin{tabular}{|c|c|c|c|c|}
\hline & $\begin{array}{l}\text { Korean adoptees (\%) } \\
N=320\end{array}$ & $\begin{array}{l}\text { Non-Korean adoptees (\%) } \\
N=1,125\end{array}$ & $\begin{array}{l}\text { Siblings of adoptees (\%) } \\
N=190\end{array}$ & $\begin{array}{l}\text { Majority population (\%) } \\
N=142,024\end{array}$ \\
\hline \multicolumn{5}{|l|}{ Year of birth } \\
\hline 1973 & 26.9 & 20.3 & 25.3 & 28.2 \\
\hline 1974 & 41.6 & 23.7 & 27.9 & 27.9 \\
\hline 1975 & 15.6 & 30.8 & 20.0 & 25.4 \\
\hline 1976 & 15.9 & 25.2 & 26.8 & 18.5 \\
\hline \multicolumn{5}{|l|}{ Maternal education } \\
\hline Short & 30.6 & 24.0 & 17.4 & 34.9 \\
\hline Medium & 29.7 & 22.8 & 14.7 & 30.9 \\
\hline Long & 23.4 & 25.4 & 28.4 & 21.6 \\
\hline Very long & 16.3 & 27.8 & 39.5 & 12.6 \\
\hline \multicolumn{5}{|l|}{ SES } \\
\hline Unclassified & 11.3 & 11.7 & 9.5 & 14.5 \\
\hline Manual workers & 10.0 & 4.6 & 2.1 & 13.0 \\
\hline Skilled workers & 11.9 & 6.3 & 6.3 & 15.5 \\
\hline White collar 1 & 11.9 & 10.0 & 12.1 & 12.7 \\
\hline White collar 2 & 28.8 & 29.1 & 24.2 & 23.8 \\
\hline White collar 3 & 26.3 & 38.3 & 45.8 & 20.5 \\
\hline \multicolumn{5}{|c|}{ Single parent household } \\
\hline Yes & 13.1 & 14.0 & 11.6 & 15.3 \\
\hline \multicolumn{5}{|l|}{ Geographic residency } \\
\hline Metropolitan area & 20.6 & 25.0 & 28.4 & 22.5 \\
\hline Other city & 56.6 & 58.6 & 51.6 & 54.1 \\
\hline Rural community & 22.8 & 16.4 & 20.0 & 23.5 \\
\hline
\end{tabular}


test scores from military conscription are presented in Table 2. The siblings had the highest mean grade points and global test scores while the non-Korean adoptees had the lowest. Korean adoptees and majority population peers were quite similar in between.

In Table 3 the mean grade points of each study group are presented in three models where the first one is adjusted for year of birth, the second for year of birth and global test scores from military conscription and the third also for household SES, maternal education, single parent household and residency. In model 1, Korean adoptees had grade points slightly above the majority population peers and siblings much higher grade points. The non-Korean adoptees had much lower grade points than the non-adopted comparisons and this was most marked for physics. For music and sports the grade points were quite similar as in the majority group. When grade points were adjusted for global test scores, the comparison between the Korean group and the majority population was almost the same as in Model 1 whereas outcomes in the non-Korean group was now strongly improved compared to the majority population. For the siblings the outcomes were still better than in the majority population but lower than before adjustment. In the third model, the differences between the both adoptee groups (most marked in the non-Korean group) and the majority population diminished-or even turned into a less advantageous outcome for the adoptees. There was also a similar development in the third model in the comparisons between the siblings and the majority population.

In Table 4 the risk of having completed the lower level only of Mathematics is presented in three

Table 2 Global test score and grade points by study group

\begin{tabular}{lllll}
\hline & $\begin{array}{l}\text { Korean adoptees } \\
\text { Mean }(95 \% \text { C.I.) }\end{array}$ & $\begin{array}{l}\text { Non-Korean adoptees } \\
\text { Mean }(95 \% \text { C.I.) }\end{array}$ & $\begin{array}{l}\text { Siblings of adoptees } \\
\text { Mean (95\% C.I.) }\end{array}$ & $\begin{array}{l}\text { Majority population } \\
\text { Mean (95\% C.I.) }\end{array}$ \\
\hline Global test score & $5.31(5.11-5.51)$ & $3.96(3.86-4.06)$ & $6.17(5.97-6.31)$ & $5.26(5.25-5.27)$ \\
Average grade point & $3.29(3.22-3.36)$ & $2.88(2.83-2.92)$ & $3.47(3.37-3.56)$ & $3.14(3.14-3.14)$ \\
Physics & $3.32(3.22-3.42)$ & $2.71(2.65-2.77)$ & $3.60(3.40-3.74)$ & $3.21(3.21-3.21)$ \\
Swedish & $3.16(3.07-3.25)$ & $2.71(2.66-2.76)$ & $3.40(3.28-3.52)$ & $2.97(2.97-2.97)$ \\
History & $3.41(3.30-3.52)$ & $2.88(2.82-2.94)$ & $3.62(3.48-3.76)$ & $3.15(3.15-3.15)$ \\
Sports education & $3.71(3.63-3.79)$ & $3.55(3.49-3.60)$ & $3.65(3.52-3.78)$ & $3.45(3.45-3.45)$ \\
Music & $3.31(3.21-3.41)$ & $3.06(3.01-3.12)$ & $3.52(3.40-3.64)$ & $3.11(3.11-3.11)$ \\
\hline
\end{tabular}

Table 3 Linear regression of mean grade points

\begin{tabular}{|c|c|c|c|c|c|}
\hline Subject & Study group & $N$ & Model 1 & Model 2 & Model 3 \\
\hline \multirow[t]{4}{*}{ Average grade point } & Korean adoptees & 320 & $0.15^{* * *}$ & $0.14^{* * *}$ & $0.12^{* * *}$ \\
\hline & Non-Korean adoptees & 1,125 & $-0.27^{* * *}$ & $0.05^{* * *}$ & -0.03 \\
\hline & Siblings of adoptees & 172 & $0.32^{* * *}$ & $0.11^{* *}$ & 0.03 \\
\hline & Majority population & 142,024 & 0 & 0 & 0 \\
\hline \multirow{4}{*}{ Physics } & Korean adoptees & 287 & 0.11 & $0.10^{*}$ & 0.08 \\
\hline & Non-Korean adoptees & 964 & $-0.46^{* * *}$ & 0.02 & $-0.07^{* *}$ \\
\hline & Siblings of adoptees & 161 & $0.39^{* * *}$ & 0.10 & 0.02 \\
\hline & Majority population & 122,471 & 0 & 0 & 0 \\
\hline \multirow[t]{4}{*}{ Swedish } & Korean adoptees & 308 & $0.16^{* * *}$ & $0.17^{* * *}$ & $0.15^{* * *}$ \\
\hline & Non-Korean adoptees & 1,051 & $-0.28^{* * *}$ & $0.09^{* * *}$ & -0.01 \\
\hline & Siblings of adoptees & 171 & $0.42^{* * *}$ & $0.19^{* * *}$ & 0.09 \\
\hline & Majority population & 133,095 & 0 & 0 & 0 \\
\hline \multirow[t]{4}{*}{ History } & Korean adoptees & 264 & $0.26 * * *$ & $0.27^{* * *}$ & $0.24^{* * *}$ \\
\hline & Non-Korean adoptees & 944 & $-0.28^{* * *}$ & $0.12^{* * *}$ & -0.03 \\
\hline & Siblings of adoptees & 154 & $0.48^{* * *}$ & $0.23^{* * *}$ & 0.11 \\
\hline & Majority population & 117,098 & 0 & 0 & 0 \\
\hline \multirow[t]{4}{*}{ Sports } & Korean adoptees & 307 & $0.26^{* * *}$ & $0.25^{* * *}$ & $0.24^{* * *}$ \\
\hline & Non-Korean adoptees & 1,047 & $0.10^{* * *}$ & $0.22^{* * *}$ & $0.16^{* * *}$ \\
\hline & Siblings of adoptees & 168 & $0.20^{* *}$ & 0.13 & 0.07 \\
\hline & Majority population & 132,272 & 0 & 0 & 0 \\
\hline \multirow{4}{*}{ Music } & Korean adoptees & 308 & $0.21 * * *$ & $0.19^{* * *}$ & $0.17^{* * *}$ \\
\hline & Non-Korean adoptees & 1,047 & -0.05 & $0.24^{* * *}$ & $0.14^{* * *}$ \\
\hline & Siblings of adoptees & 170 & $0.42^{* * *}$ & $0.24^{* * *}$ & $0.16^{*}$ \\
\hline & Majority population & 132,467 & 0 & 0 & 0 \\
\hline
\end{tabular}

Model 1 is adjusted for year of birth. Model 2 is adjusted for year of birth and test scores. Model 3 is adjusted for year of birth, test scores, SES, maternal education, single parent household and residency

* Significant difference $P<0.05$, ** Significant difference $P<0.01$, ** Significant difference $P<0.001$ 
Table 4 Logistic regression in conscripts with complete test scores of having completed the lower level of mathematics only in ninth grade

\begin{tabular}{llll}
\hline Korean adoptees & $0.7(0.5-0.9)$ & $0.6(0.4-0.8)$ & $0.7(0.5-0.9)$ \\
Non-Korean adoptees & $1.9(1.7-2.7)$ & $0.6(0.5-0.8)$ & $1.1(1.0-1.3)$ \\
Siblings of adoptees & $0.3(0.2-0.5)$ & $0.5(0.3-0.7)$ & $0.7(0.4-1.1)$ \\
Majority population & 1 & 1 & 1
\end{tabular}

Model 1 is adjusted for year of birth. Model 2 is adjusted for year of birth and test scores. Model 3 is adjusted for year of birth, test scores, SES, maternal education, single parent household and residence

Table 5 Logistic regression in conscripts with complete test scores of having completed the lower level of English only in ninth grade

\begin{tabular}{llll}
\hline Korean adoptees & $0.6(0.5-0.8)$ & $0.6(0.4-0.8)$ & $0.7(0.5-0.9)$ \\
Non-Korean adoptees & $1.5(1.3-1.7)$ & $0.6(0.5-0.8)$ & $1.0(0.8-1.1)$ \\
Siblings of adoptees & $0.5(0.3-0.7)$ & $0.5(0.3-0.7)$ & $1.1(0.7-1.6)$ \\
Majority population & 1 & 1 & 1
\end{tabular}

Model 1 is adjusted for year of birth. Model 2 is adjusted for year of birth and test scores. Model 3 is adjusted for year of birth, test scores, SES, maternal education, single parent household and residency

models. The first model is only adjusted for year of birth and demonstrates the over-risk in non-Korean adoptees and the under-risk for siblings. In model 2, adjusted also for test scores, the risks are lower in the two adoptee groups and in the sibling group, compared to majority population peers. The risk figures increase slightly in model 3, which is adjusted also for SES, maternal education, single parent household and residency and this is most evident for non-Korean adoptees. The pattern is similar for having completed the lower level only of English (Table 5).

\section{Discussion}

In this register study, the relation between cognitive function and school performance in male adolescent adoptees was studied by use of global scores from intelligence tests at military conscription and grade points from the 9th school year. Grade points in theoretical subjects were lower in the non-Korean adoptees than in the male majority population, but when global test scores were adjusted for, outcome was significantly better (equal for physics) than in the majority population. The grade points of the Korean adoptees were higher than in the majority population, also after adjustment for global test scores.

The outcomes for the non-Korean adoptees seem to contradict the hypothesis of an "adoption decalage" (= school performance in adoptees not as good as expected from IQ) [8]. These adoptees performed better-reached higher grade points - than could be expected from the cognitive test scores. It is also striking that their grade point pattern differed from the other groups with the lowest levels on physics and the highest on sports and music with Swedish and history grade points in between. This pattern also supports the hypothesis that the poorer school performance is related to a lower than average cognitive competence. Using the "adoption decalage" hypothesis as the main hypothesis for understanding poor school performance in non-Korean adoptees may divert attention from existing cognitive deficits in international adoptees with learning difficulties. In contrast our results indicate that an assessment of cognitive competence is an important step for successful educational interventions for many non-Korean adoptees and for preventing secondary psychological symptom formation due to unrealistic expectations.

The school performance of Korean adoptees is quite different. They perform as well as, or better than, the majority population. As shown previously, their test scores are also slightly higher than in the majority population while the non-Korean adoptees score much lower [10]. There are three possible explanations to these differences concerning cognitive prerequisites. Firstly, during the period in focus most Korean adoptees were selected for international adoption since they were born "out of wedlock" and relinquished by their mothers due to socio-cultural prejudices toward single parenthood $[20,21]$, not for reasons related to chronic poverty or parental psychopathology which may affect adopted children's long-term development negatively. Secondly, the quality of care before adoption was well developed in South Korea already by the 70s [22]. Thirdly, the control of adoption agencies was also well developed [23]. These three factors-selection, care and control-probably vary considerably more in other countries of origin [24, 25].

It is well established that adoption has a potential of increasing the IQ of the adoptee. French national adoption studies, using a sibling-proband design, found that infant adoption had a positive effect on children's cognitive development, and that this process was positively correlated with the socio-educational background of the adoptive family [26, 27]. The results were also replicated in a study of late adoptions (4-6 years) of neglected or abused children [28]. The educationally stimulating qualities of the adoptive families-and more specifically the socioeconomic prerequisites-are illustrated by the attenuation of differences of mean grade points between the adoptee groups and the majority population when socio-economic variables were also adjusted for (Table 3, model 3). Similar conclusions can be drawn from the increasing risks in non-Korean adoptees for choosing the lower levels of mathematics and English after adjustment for socio-economic variables (Tables 4, 5, model 3). The education stimulating 
qualities are also expressed by higher than average grade points in the sibling group after adjusting for global test scores. The even larger differences in comparison with majority population peers in the models adjusted only for age demonstrate the good mean cognitive function in this sibling group.

The tests scores reflect functioning (at conscription) about 2 years after having finished ninth grade. High grade points may be followed by an IQ-stimulating environment and vice versa. The magnitudes of the effects of cognitive ability on the grade point averages may thus have been slightly inflated even though this would most probably only to a limited extent have influenced the major results. It is also important to note that the test battery is highly influenced by verbal competencies, which may yield poorer performance in culturally and socially disadvantaged groups [29].

The fact that the conscription test of cognitive ability is secret creates some uncertainty about how the results should be interpreted and how they relate to results from other established cognitive tests, even if this limitation to a certain degree is balanced by the theoretical and empirical bases of these tests, the available surveying descriptions of the subscales, the referred examination of the construct validity and the comprehensive previous research using these registers.

The attrition at conscription was highest among the non-Korean adoptees, the group with lowest test scores and grades. The most common reasons for exemption from conscription are severe somatic or psychosocial handicaps (e.g., an adolescent history of serious delinquency and/or mental ill health) [30]. This means that the differences between the nonKorean adoptees and the other groups concerning test scores and school grades may have been underestimated. However, this difference in attrition rates has most likely only had a marginal influence on the analyses of relations between test scores and school performance.
The cognitive prerequisites of international adoptees seem to be related to the selection of children given away for adoption, and also on the quality of care provided to the pregnant mother and to the child from time of birth to the actual adoption [10]. These conditions vary between countries and probably also over time. Thus, our results concerning levels of test scores and grade points are not necessarily valid for other samples of adoptees that, for instance, were born later than our study groups or had other geographic origins. However, there is no reason to believe that the main finding of this study-higher grade points than expected from intelligence test-should be radically different. Finally, it is not clear whether the results can be generalized to females who constitute around $60 \%$ of Swedish international adoptees.

\section{Conclusions}

This study demonstrates that male international adoptees in Sweden perform better in school than could be expected from their cognitive competence. These positive results can probably be explained by the educationally stimulating environment that the adoptive families provide. The obvious implication for practise is that poor school performance in individual adoptees should first be addressed with a cognitive assessment. Hypotheses about psychological problems related to the status of being an adoptee (e.g., "identity problems") should not be used as a general explanation without a preceding cognitive assessment. Finally, comparisons and compilations of adoption studies should take differences related to geographic origin into consideration.

Acknowledgments This study was supported by grants from The Bank of Sweden Tercentenary Foundation. The research position of Frank Lindblad is financed by the Swedish Council for Working Life and Social Research.

\section{References}

1. Verhulst FC, Althaus M, Versluis-den Bieman HJ (1990) Problem behavior in international adoptees: I. An epidemiological study. J Am Acad Child Adolesc Psychiatry 29:94-103

2. Tieman W, van der Ende J, Verhulst FC (2005) Psychiatric disorders in young adult intercountry adoptees: an epidemiological study. Am J Psychiatry 162:592-598
3. Hjern A, Lindblad F, Vinnerljung B (2002) Suicide, psychiatric illness and social maladjustment in inter-country adoptees in Sweden. Lancet 360:443448

4. Juffer F, van IJzendoorn MH (2005) Behavior problems and mental health referrals of international adoptees: a meta-analysis. JAMA 293:2501-2515
5. Jablonska B. Lindberg L, Lindblad F, Hjern A (2008) School performance and hospital admissions because of self-harm-a Swedish national cohort study (submitted)

6. Reynolds AJ, Temple JA, Ou SR, Robertson DL, Mersky JP, Topitzes JW, Niles MD (2007) Effects of a schoolbased, early childhood intervention on adult health and well-being: a 19-year follow-up of low-income families. Arch Pediatr Adolesc Med 161:730-739 
7. van IJzendoorn MH, Juffer F, Poelhuis CW (2005) Adoption and cognitive development: a meta-analytic comparison of adopted and nonadopted children's IQ and school performance. Psychol Bull 131:301-316

8. Winick M, Meyer KK, Harris RC (1975) Malnutrition and environmental enrichment by early adoption. Science 190:1173-1175

9. Stams GJ, Juffer F, Rispens J, Hoksbergen RA (2000) The development and adjustment of 7-year-old children adopted in infancy. J Child Psychol Psychiatry 41:1025-1037

10. Odenstad A, Hjern A, Lindblad F, Rasmussen F, Vinnerljung B, Dalen M (2008) Does age at adoption and geographic origin matter? A national cohort study of cognitive test performance in adult intercountry adoptees. Psychol Med, Mar 26:1-8 [Epub ahead of print]

11. Lindblad F, Hjern A, Vinnerljung B (2003) Inter-country adopted children as young adults-a Swedish cohort study. Am J Orthopsychiatry 73:190202

12. Dalen $M$, Lindblad F, Odenstad A, Rasmussen F, Vinnerljung B, Hjern A (2008) Educational attainment and cognitive competence in adopted men - a study of international and national adoptees, siblings and a general Swedish population. Child Youth Serv Rev 30:1211-1219

13. Rosén M (2002) National health data registers: a Nordic heritage to public health. Scand J Public Health 30:81-85
14. www.mia.eu/statistik/varlds.pdf

15. Slavin RE (1987) Ability grouping and student achievement in elementary schools: a best-evidence research synthesis. Rev Educ Res 57:293-336

16. www.skolverket.se. Stockholm: the Swedish National Agency for Education

17. Carlstedt B (2000) Cognitive abilities-aspects of structure, process and measurement. Dissertation. Gothenburg Studies in Educational Sciences, University of Gothenburg

18. Carlstedt B, Mårdberg B (1993) Construct validity of the Swedish Enlistment Battery. Scand J Psychol 34:353362

19. Statistics Sweden (1982) Socio-economic classification (SEI). Stockholm: SCB

20. Tahk Y (1986) Intercountry adoption program in Korea; policy, law and services. In: Hoksbergen RA-C (ed) Adoption in worldwide perspective. Swets \& Zeitlinger, Lisse, pp 79-91

21. Kim WJ (1995) International adoptiom: a case review of Korean children. Child Psychiatry Hum Dev 25:141-154

22. Chandra A, Abma J, Maza P, Bachrach C (1999) Adoption, adoption seeking, and relinquishment for adoption in the United States. Adv Data 11:1-16

23. Kim C, Carroll TG (1975) Intercountry adoption of South Korean orphans: a lawyer's guide. J Fam Law 14:223-253

24. Triseliotis J (2000) Intercountry adoption. Global trade or global gift. Adopt Foster 24:45-54
25. Fonseca C (2002) Un expected reversal. Charting the course of international adoption in Brazil. Adopt Foster 26:2839

26. Dumaret A (1985) IQ, Scholastic Performance and Behaviour of Sibs raised in contrasting Environments. J Child Psychol Psychiatry 26:553-580

27. Duyme M (1988) School success and social class: an adoption study. Dev Psychol 24:203-209

28. Duyme M, Dumaret A-C, Tomekiewicz S (1999) How can we boots IQs of "dull children"?: A late adoption study. PNAS 96:8790-8794

29. Skuy M, Taylor M, O'Carroll S, Fridjhon P, Rosenthal L (2000) Performance of black and white South African children on the Wechsler Intelligence Scale for Children-revised and the Kaufman Assessment Battery. Psychol Rep 86:727-737

30. Vinnerljung B (1996) Fosterbarn som vuxna [Foster children as adults]. Arkiv, Lund 